\title{
Effects of intrauterine infusion of Escherichia coli lipopolysaccharide on uterine health, resolution of purulent vaginal discharge, and reproductive performance of lactating dairy cows
}

\author{
João G. N. Moraes, ${ }^{*} \dagger^{1}$ Paula R. B. Silva, ${ }^{\dagger} \dagger$ Luís G. D. Mendonça, ${ }^{*}$ Alexandre A. Scanavez, ${ }^{*}$ \\ Joseane C. C. Silva, ${ }^{*}$ and Ricardo C. Chebel ${ }^{*} \dagger \ddagger \S^{2}$ \\ *Department of Veterinary Population Medicine, and \\ †Department of Animal Science, University of Minnesota, St. Paul 55108 \\ $\ddagger$ Department of Large Animal Clinical Sciences, and \\ §Department of Animal Sciences, University of Florida, Gainesville 32608
}

\begin{abstract}
The objectives of the current experiment were to evaluate the effects of intrauterine infusion of Escherichia coli lipopolysaccharide (LPS) in cows diagnosed with purulent vaginal discharge (PVD) on intrauterine cell population, resolution of PVD, uterine health, and reproductive performance. Jersey cows $(\mathrm{n}=3,084)$ were examined using the Metricheck device to diagnose PVD at $35 \pm 6 \mathrm{~d}$ postpartum. Purulent vaginal discharge was defined as the presence of purulent ( $\geq 50 \%$ pus) discharge detectable in the vagina. Of the 310 cows positive for PVD, 267 cows were enrolled in the current experiment. To ensure proper timing of treatment and collection of samples, only 9 PVD-positive cows were treated per day. Selected cows were balanced at $35 \pm$ $6 \mathrm{~d}$ postpartum for lactation number, body condition score, and milk yield and were randomly assigned to receive an intrauterine infusion of $20 \mathrm{~mL}$ of phosphatebuffered saline (PBS; control, $\mathrm{n}=87$ ), $20 \mathrm{~mL}$ of PBS with $150 \mu \mathrm{g}$ LPS (LPS150, $\mathrm{n}=91$ ), or $20 \mathrm{~mL}$ of PBS with $300 \mu \mathrm{g}$ of LPS (LPS300, $\mathrm{n}=89$ ). Uterine cytology was performed immediately before treatment and 1,2 , and $7 \mathrm{~d}$ after treatment to evaluate the effect of LPS treatment on intrauterine cell population. Cows were examined with the Metricheck device at 7 and $28 \mathrm{~d}$ after treatment to evaluate the effects of treatment on resolution of PVD. Reproductive status was recorded up to $200 \mathrm{~d}$ postpartum. Cows diagnosed with PVD had greater incidence of twinning, dystocia, retained placenta, and metritis after calving than cows without PVD. Count of polymorphonuclear leukocytes (PMNL)
\end{abstract}

Received June 16, 2016.

Accepted October 12, 2016.

${ }^{1}$ Current address: Division of Animal Sciences, University of Missouri, Columbia, MO.

${ }^{2}$ Corresponding author: rcchebel@ufl.edu in uterine cytology 1,2 , and $7 \mathrm{~d}$ after intrauterine infusion was not statistically different among treatments. From d 0 to 1, however, PMNL count in uterine cytology of PBS cows increased by $5 \%$, whereas the PMNL count in uterine cytology of LPS150 and LPS300 cows increased by 54 and $48 \%$, respectively. Treatment did not affect the likelihood of cows being diagnosed with PVD 7 and $28 \mathrm{~d}$ after intrauterine infusion. Cows without PVD and LPS150 cows were more likely to be pregnant after the first postpartum AI than PBS cows. After the second postpartum AI, cows without PVD were more likely to be pregnant than PBS and LPS300 cows. Hazard of pregnancy up to $200 \mathrm{~d}$ postpartum was decreased for PBS and LPS300 cows compared with cows without PVD, and it tended to be decreased for LPS150 cows compared with cows without PVD. Intrauterine treatment with $150 \mu \mathrm{g}$ of $E$. coli LPS of cows diagnosed with PVD improved likelihood of pregnancy after the first postpartum AI, but further research is needed to elucidate the mechanism by which LPS treatment improved fertility.

Key words: lactating dairy cow, purulent vaginal discharge, lipopolysaccharide

\section{INTRODUCTION}

Purulent vaginal discharge (PVD), formerly known as clinical endometritis (Dubuc et al., 2010), has a negative effect on profitability of cattle industries because of infertility, increased culling for reproductive failure, reduced milk yield, and costs associated with treatment (Sheldon et al., 2009). The term PVD has been proposed for use in place of clinical endometritis because endometrial inflammation is not always present in cows with PVD (Dubuc et al., 2010). Occurrence of dystocia, twinning, retained fetal membranes, stillbirth, abortion, and metritis predispose cows to PVD (Galvão, 2012). Treatment of cows that were at high risk of developing uterine disease at $24 \mathrm{~h}$ after parturition with 
ceftiofur crystalline free acid reduced the probability of PVD at $35 \pm 3$ d postpartum (Dubuc et al., 2011). Treatment of cows at high risk for uterine diseases with systemic antimicrobials, however, does not necessarily improve their reproductive performance (Dubuc et al., 2011; McLaughlin et al., 2013). Intrauterine treatment of cows with PVD using cephapirin benzathine is approved in Canada, Europe, and New Zealand, and it is reported to increase reproductive performance (LeBlanc et al., 2002a; Kasimanickam et al., 2005). In the United States, no products for intrauterine treatment of lactating dairy cows containing cephapirin benzathine are available. Other intrauterine antimicrobial therapies may inhibit phagocytic activity of neutrophils in the uterus (Masera et al., 1980), compromising resolution of uterine infections. Additionally, the increased scrutiny of the use of antimicrobials relevant for human medicine in food-producing animals may require the development of non-antimicrobial strategies for the treatment of diseases.

Lipopolysaccharide is an important bacterial molecule that stimulates pathogen recognition receptors and triggers inflammatory response (Mogensen, 2009). In mammals, transcription factors such as nuclear factor- $\kappa \mathrm{B}$ and IFN regulatory factor family are activated (O'Neill and Bowie, 2007; Lu et al., 2008) upon recognition of LPS by the toll-like receptor 4 and myeloid differentiation factor 2 complex (Park et al., 2009), causing the secretion of cytokines and chemokines that regulate innate and adaptive immunity $(\mathrm{Li}$ and Verma, 2002; Schroder et al., 2004). Additionally, LPS stimulates NADPH oxidase activation, leading to production of large amounts of superoxide, a key product associated with the killing ability of PMNL (Huang et al., 2009). Intrauterine infusion of endometritic cows with $100 \mu \mathrm{g}$ of Escherichia coli LPS resulted in elimination of uterine bacterial infection in $75 \%$ of treated cows and increased intrauterine total leukocyte count, the proportion of PMNL in uterine cytology, and the proportion of live PMNL in the uterus (Singh et al., 2000). Additionally, 8 of the 12 cows treated with LPS conceived, whereas only 1 of the 12 untreated control cows conceived (Singh et al., 2000).

The hypothesis of the current experiment was that intrauterine treatment of cows with PVD with $E$. coli LPS would increase the number of PMNL in the uterine cytology, resolve PVD, improve pregnancy per AI (P/AI) after first and second postpartum AI, and improve pregnancy rate up to 200 DIM. The objectives of the present experiment were to evaluate the effects of intrauterine infusion of LPS in cows with PVD on intrauterine cell population, uterine health, and reproductive performance of lactating dairy cows.

\section{MATERIALS AND METHODS}

\section{Animals, Treatments, and BCS}

Lactating Jersey cows $(\mathrm{n}=3,084)$ from a freestall dairy located in Nicollet (MN) were examined for PVD at $35 \pm 6$ DIM using the Metricheck device (Simcro, Hamilton, New Zealand; McDougall et al., 2007) from December 2010 to May 2012. Four hundred twenty (14\%) cows had $\geq 50 \%$ pus in the vaginal exudate and were considered positive for PVD. All cows with PVD were examined by palpation per rectum, and 110 cows were determined to have large amounts of fluid in the uterus. These cows were considered to have a different and more severe uterine pathology (i.e., pyometra) compared with cows with PVD without a fluid-filled uterus and were, therefore, not included in the present experiment.

At PVD diagnosis, the retrieved exudate was placed on a black plastic plate to improve the visualization of the discharge. The purulent discharge was scored based on the amount of pus present in the exudate retrieved by the Metricheck device. Scores were given according to the following classification: mild (retrieved exudate contained approximately $50-60 \%$ of pus), moderate (retrieved exudate contained approximately 60-90\% of pus), and severe (retrieved exudate contained approximately $90-100 \%$ pus). Of the 310 cows positive for PVD without large amounts of uterine fluid, 267 were used in the present experiment. To ensure proper and timely treatment of cows and collection and processing of samples, only 9 cows were enrolled per day, with 3 cows per treatment enrolled per day. Only 43 cows with PVD were not enrolled (10\% of cows positive for PVD).

Enrolled cows were balanced for lactation number, BCS ( $1=$ emaciated, $5=$ obese; Ferguson et al., 1994), PVD score (mild, moderate, severe), and weekly average milk yield up to 28 DIM. Blocks of 3 cows were created, and treatments were randomly assigned to the cows within blocks using a sealed envelope. Cows assigned to the PBS treatment $(\mathrm{n}=87)$ received an intrauterine infusion of $20 \mathrm{~mL}$ of PBS, cows assigned to the LPS150 treatment $(\mathrm{n}=91)$ received an infusion of $20 \mathrm{~mL}$ of PBS containing $150 \mu \mathrm{g}$ of E. coli LPS (E. coli serotype 026:B6, containing 10,000 endotoxin units per milligram of LPS; Sigma-Aldrich, St. Louis, MO), and cows assigned to the LPS300 treatment ( $\mathrm{n}=$ 89) received an intrauterine infusion of $20 \mathrm{~mL}$ of PBS containing $300 \mu \mathrm{g}$ of LPS. Lyophilized LPS from E. coli serotype 026:B6 containing 10,000 endotoxin units per milligram of LPS (cat. no. L8274; Sigma-Aldrich) was reconstituted by adding $1 \times$ sterile PBS $(\mathrm{pH} 7.4,137$ $\mathrm{m} M$ sodium chloride, $2.7 \mathrm{~m} M$ potassium chloride, 12 
$\mathrm{m} M$ phosphate buffer; cat. no. E504; Amresco LLC, Solon, $\mathrm{OH}$ ), and solutions at $1 \mathrm{mg} / \mathrm{mL}$ were stored in silanized containers (cat. no. 27225-U; Sigma-Aldrich) at $-80^{\circ} \mathrm{C}$. The solutions of LPS used for the intrauterine treatments (150 and $300 \mu \mathrm{g}$ of LPS) were prepared each morning before infusions, using glassware that had been previously treated with SIGMACOTE (cat. no SL2; Sigma-Aldrich) to inhibit LPS from binding to the glassware. The LPS solutions were transported inside a cooler without icepacks from the farm's laboratory to the pens, and solutions were at room temperature when infused in the uterus. For the intrauterine infusions, an infusion pipette (Infuse-Eze Pipette; Jorgenson Labs, Loveland, CO) was directed to the base of the larger uterine horn (when the distinction was possible) and solutions were infused. Cows received the intrauterine infusion $24 \mathrm{~h}$ after diagnosis of PVD.

The safety of the doses of LPS used in the current experiment were determined based on a pilot experiment in which nonlactating cows that received intrauterine infusions of 100, 150, 200, 250, and $450 \mu \mathrm{g}$ of LPS diluted in $20 \mathrm{~mL}$ of PBS did not have any systemic (e.g., rectal temperature, rumination, heart rate) alterations (J. G. N. Moraes and R. C. Chebel, unpublished data). Furthermore, the LPS doses used in the current experiment were determined based on the pilot experiment in which the increase in PMNL isolated from uterine cytology $20 \mathrm{~h}$ after LPS intrauterine infusion was quadratic, with maximum PMNL count observed when LPS doses $\geq 200 \mu \mathrm{g}$ (J. G. N. Moraes and R. C. Chebel, unpublished data).

\section{Production Parameters and Prevalence of Postpartum Disorders}

Cows were milked thrice daily and all cows received recombinant bST (500 mg of Posilac; Elanco Animal Health, Greenfield, IN) every $10 \mathrm{~d}$ starting at $57 \pm 3$ DIM. Monthly, milk yield, milk fat and protein content, and SCC were recorded for individual cows during the official DHIA test. Data regarding milk yield, milk fat and protein content, and SCC were collected from calving to $200 \mathrm{~d}$ postpartum. Energy-corrected milk was calculated for each cow using the formula

$$
\begin{gathered}
\operatorname{ECM}(\mathrm{kg})=[(\mathrm{kg} \text { of milk }) \times 0.327]+[(\mathrm{kg} \text { of fat }) \\
\times 12.95]+[(\mathrm{kg} \text { of protein }) \times 7.2] .
\end{gathered}
$$

Prevalence of dystocia, twins, male calf, retained fetal membrane, and metritis were recorded for all cows examined for PVD. Calving ease score was recorded for all cows immediately after calving. Calving ease score was defined as follows: $1=$ unassisted calving in the close-up pen; $2=$ unassisted calving in the maternity pen; 3 = slight difficulty, assisted calving (e.g., correction of calf presentation, position, or posture); $4=$ difficult calving (e.g., correction of calf presentation, position, or posture or significant traction applied); and $5=$ extremely difficult calving (e.g., fetotomy, cesarean section). Cows with calving ease score of 3 to 5 were classified as having dystocia. No cows enrolled in the experiment had a calving ease score of 5 .

During the postpartum period (2-21 DIM), cows were observed daily by the herd veterinarian and trained farm personnel to detect common postpartum diseases. Retained fetal membrane was defined as cows not having complete separation of retained fetal membranes by $24 \mathrm{~h}$ after calving. All cows presenting any clinical signs of postpartum diseases were palpated, and cows with an enlarged uterus containing watery, fetid, reddish-brownish uterine discharge were classified as having metritis. Cows diagnosed with metritis received systemic treatment with ceftiofur hydrochloride sterile suspension (20 mL of Excenel RTU EZ; Pfizer Animal Health, Madison, NJ) for 4 consecutive days. Cows with abnormal uterine discharge on d 5 after onset of treatment were retreated with ceftiofur hydrochloride sterile suspension (20 mL of Excenel RTU EZ) for 3 additional days.

\section{Effect of Treatment on Uterine Cell Population and Resolution of PVD}

To determine the effects of treatment on intrauterine cell population, cows with PVD had uterine cytology performed before intrauterine infusion (d 0) and 1, 2, and $7 \mathrm{~d}$ after treatment. Cytology was performed using the cytobrush (Cytobrush Plus, Cooper Surgical Inc., Trumbull, CT) technique. Endometrial samples were collected from the base of the larger horn, presumably the previously gravid horn (when the distinction was possible). After sample collection, the cytobrush was rolled onto a clean microscope glass slide, which was stained with modified Wright-Giemsa stain (ProtocolHema3, Biochemical Sciences, Swedesboro, NJ). Slides were evaluated twice under $\times 400$ magnification by one examiner who was blinded to treatments and the interval between treatment and sample collection. In each evaluation, 100 cells, excluding erythrocytes, were counted for a total of 200 cells counted per slide. The percentages of cows with $\geq 10 \%$ of PMNL in uterine cytology were determined (Sheldon et al., 2006). To determine the effects of intrauterine infusion with LPS on PVD resolution, cows with PVD were re-examined with the Metricheck device at 7 and $28 \mathrm{~d}$ after treatment. Resolution of PVD was characterized by presence of $<50 \%$ of pus in the exudate retrieved from the vagina. 
One hundred eight cows were submitted to uterine biopsy (Moraes et al., 2017), and uterine cytology and Metricheck at d 7 and 28 were therefore not performed in these cows because of possible inherent trauma during the procedures. Therefore, data regarding uterine cytology and resolution of PVD from 159 cows (PBS $=51, \operatorname{LPS} 150=54$, and LPS300 $=54$ ) were analyzed.

\section{Reproductive Management and Responses}

Cows were presynchronized with 3 injections of $\mathrm{PGF}_{2 \alpha}$ given $41 \pm 3,55 \pm 3$, and $69 \pm 3$ DIM. Voluntary waiting period was 50 DIM. Cows not inseminated in estrus by $81 \pm 3$ DIM were enrolled in the Ovsynch56 protocol ( $\mathrm{GnRH}, 7$ d later $\mathrm{PGF}_{2 \alpha}, 56 \mathrm{~h}$ later $\mathrm{GnRH})$ and were inseminated at fixed time at $91 \pm 3$ DIM. Cows were re-inseminated upon detected estrus. From December 2010 to September 2011, cows not reinseminated by $35 \pm 6 \mathrm{~d}$ after AI received an injection of $\mathrm{GnRH}$ and if diagnosed not pregnant $7 \mathrm{~d}$ later $(38 \pm$ $3 \mathrm{~d}$ after $\mathrm{AI}$ ) received a $\mathrm{PGF}_{2 \alpha}$ injection, an injection of GnRH 56 h later, and timed AI 16 h later. From February to May 2012, cows not re-inseminated upon detected estrus by $35 \pm 6 \mathrm{~d}$ after AI were examined by ultrasound $(5 \mathrm{MHz}$, Ibex Lite; E. I. Medical Imaging, Loveland, CO) for pregnancy diagnosis. Nonpregnant cows bearing a corpus luteum $\geq 20 \mathrm{~mm}$ in diameter received a $\mathrm{PGF}_{2 \alpha}$ injection $2 \mathrm{~d}$ after the nonpregnancy diagnosis and were observed for estrus for $12 \mathrm{~d}$. If not re-inseminated within $12 \mathrm{~d}$ of $\mathrm{PGF}_{2 \alpha}$ treatment, they were enrolled in the Ovsynch 56 protocol. Nonpregnant cows that did not have a corpus luteum $\geq 20 \mathrm{~mm}$ in diameter were treated with GnRH injection at nonpregnancy diagnosis and were enrolled in the Ovsynch 56 protocol $7 \mathrm{~d}$ later if not re-inseminated upon detection of estrus. Cows diagnosed pregnant at $35 \pm 6 \mathrm{~d}$ after AI were re-examined $66 \pm 3 \mathrm{~d}$ after AI.

Percentages of cows receiving the first and second postpartum AI upon detected estrus, the average DIM at first and second postpartum AI, the average interval between first and second postpartum AI, percentages of cows pregnant to the first and second postpartum $\mathrm{AI}$, and incidences of pregnancy loss after first and second postpartum AI were calculated. Additionally, the hazard of pregnancy up to 200 DIM, average interval from calving to pregnancy, percentage of cows deemed not eligible to be inseminated (do not breed) up to 200 DIM, and percentage of cows that failed to conceive by 200 DIM were calculated. Reproductive data referent to 2,664 cows without PVD, 87 cows with PVD treated with PBS, 91 cows with PVD treated with $150 \mu \mathrm{g}$ of LPS, and 89 cows with PVD treated with $300 \mu \mathrm{g}$ of LPS were used in the analyses.

\section{Statistical Analysis}

Sample sizes were calculated to provide sufficient power to determine statistical significances while preventing type I $(\alpha=0.05)$ and type II $(1-\beta=0.80)$ errors. Therefore, a sample size of 80 cows/treatment would be sufficient to demonstrate statistical significance when the $\mathrm{P} / \mathrm{AI}$ following first postpartum AI differed by 15 percentage units between cows with PVD treated with LPS (expected $\mathrm{P} / \mathrm{AI}=40 \%$ ) and cows with PVD left untreated (expected P/AI $=25 \%$ ). Furthermore, a sample size of 50 cows/treatment would be sufficient to demonstrate statistical significance when the difference in PMNL count in uterine cytology between treatments differed by 28 cells and the standard deviation was 50 cells. All statistical analyses were conducted using SAS 9.4 (SAS Institute Inc., Cary, NC).

The distribution of parity (primiparous vs. multiparous) among treatments was analyzed by chi-squared using the FREQ procedure. Incidences of dystocia, twins, male calf, retained fetal membranes, and metritis were analyzed by logistic regression using the LOGISTIC procedure. All models included treatment, cohort (weekly cohort of cows enrolled), and parity. In the model to evaluate the differences among treatments regarding the incidence of retained fetal membranes, the prevalence of dystocia, twins, and male calf were included as independent variables. In the model to evaluate the differences among treatments regarding the incidence of metritis, the prevalence of dystocia, twins, male calf, and retained fetal membranes were included as independent variables. Nonsignificant $(P$ $>0.10$ ) variables were removed from the model by a backward stepwise elimination procedure based on the Wald's statistics criterion. Energy-corrected milk yield in the first 90 DIM and BCS at enrollment (only from cows with PVD) were analyzed by ANOVA using the GLM procedure. The models included treatment, cohort, parity, twins, calf sex, dystocia, retained fetal membranes, metritis, and displacement of abomasum. Nonsignificant $(P>0.10)$ variables were removed from the model by a manual backward stepwise elimination procedure. Treatment was forced into all models.

The residuals of the ANOVA of the raw values of PMNL count in uterine cytology were normally distributed. Pretreatment PMNL count in uterine cytology was analyzed by ANOVA using the GLM procedure (SAS Institute Inc.). The model included treatment, cohort, parity, twins, calf sex, dystocia, BCS, retained fetal membranes, metritis, ECM in the first 90 DIM, and PVD score. The PMNL count in uterine cytology on $\mathrm{d} 1$ and 2 were analyzed as repeated measures by ANOVA using the MIXED procedure (SAS Institute 
Inc.) because of their proximity to treatment and to each other. Cow was used as the random effect, and cows were nested within treatment. The model included treatment, cohort, parity, twins, calf sex, dystocia, BCS, retained fetal membranes, metritis, ECM in the first 90 DIM, PVD score, PMNL count in uterine cytology at enrollment, day, and the interaction between treatment and day. Nonsignificant $(P>0.10)$ variables were removed from the model by a manual backward stepwise elimination procedure. The PMNL count on $\mathrm{d}$ 7 after treatment was analyzed by ANOVA using the GLM procedure with a model that included treatment, cohort, parity, twins, calf sex, dystocia, BCS, retained fetal membranes, metritis, ECM in the first 90 DIM, PVD score, and PMNL count in uterine cytology on d 2 .

Dichotomous data such as presence (yes vs. no) of $\geq 10 \%$ PMNL in uterine cytology $(0,1,2$, and $7 \mathrm{~d}$ after treatment), presence of PVD 7 and $28 \mathrm{~d}$ after treatment, pregnancy outcomes after the first and second postpartum AI, pregnancy loss after the first and second postpartum AI, whether or not cows were determined not eligible to receive AI by 200 DIM, and whether or not cows failed to conceive by 200 DIM were analyzed by logistic regression using LOGISTIC procedure (SAS Institute Inc.). All models included treatment, cohort, parity, twins, calf sex, dystocia, BCS, retained fetal membranes, metritis, and ECM in the first 90 DIM as independent variables. In the models to evaluate pregnancy outcomes and pregnancy loss the following variables were added: DIM at AI, type of breeding (estrus vs. timed AI), AI technician, and uterine biopsy (yes vs. no). Nonsignificant $(P>0.10)$ variables were removed from the model by a backward stepwise elimination procedure based on the Wald's statistics criterion.

The hazard of pregnancy up to 200 DIM was analyzed by Cox proportional hazard model using the PHREG procedure (SAS Institute Inc.). Treatment, cohort, parity, twins, calf sex, dystocia, BCS, retained fetal membranes, metritis, and ECM in the first 90 DIM were offered to the model. Variables with $P>$ 0.10 were removed by a backward stepwise elimination procedure based on the Wald's statistics criterion until all variables that remained in the model had $P \leq 0.10$. Kaplan-Meyer survival analysis (LIFETEST procedure) was used to evaluate the interval from calving to establishment of pregnancy.

Milk yield and milk components up to 200 DIM were analyzed by ANOVA for repeated measures using MIXED procedure. All models included treatment, cohort, parity, twins, calf sex, dystocia, BCS, retained fetal membranes, metritis, test month, and the interaction between treatment and test month. Variables with
$P>0.10$ were removed by a manual backward stepwise elimination procedure. Statistical significance was defined as $P \leq 0.05$ and statistical tendencies as $0.05<$ $P \leq 0.10$.

\section{RESULTS}

\section{Body Condition Score, Health Disorders, and Milk Yield}

Body condition score at $35 \pm 6$ DIM was not $(P=$ 0.29 ) different among treatments (PBS $=2.95 \pm 0.07$, LPS150 $=2.94 \pm 0.07$, LPS300 $=3.05 \pm 0.07)$. No differences $(P=0.97)$ were found among treatments regarding the percentage of primiparous cows (PBS = 45 , LPS150 $=47$, LPS300 $=45$, cows without PVD $=$ $45 \%$ ). Energy-corrected milk yield during the first 90 DIM was not different $(P=0.64)$ among treatments $(\mathrm{PBS}=23.65 \pm 1.45, \mathrm{LPS} 150=25.38 \pm 1.47, \mathrm{LPS} 300$ $=24.69 \pm 1.46$, cows without PVD $=24.54 \pm 1.18$ $\mathrm{kg} / \mathrm{d})$. Similarly, ECM yield up to 200 DIM was not affected $(P=0.22)$ by treatment $(\mathrm{PBS}=28.33 \pm 1.17$, LPS150 $=30.07 \pm 1.16$, LPS300 $=29.64 \pm 1.16$, no $\mathrm{PVD}=28.80 \pm 0.95 \mathrm{~kg} / \mathrm{d}$ ).

The likelihood of delivering a male calf was not associated $(P=0.55)$ with treatment, and $48 \%$ of cows enrolled in the experiment delivered at least one male calf (Table 1). The percentage of cows delivering twins was $2 \%$. A tendency existed $(P=0.06)$ for treatment to be associated with delivery of twins because LPS150 cows were more likely $(P=0.02)$ to have delivered twins than cows without PVD (Table 1). The incidence of dystocia was $4 \%$ and treatment was associated $(P$ $<0.01)$ with prevalence of dystocia because cows diagnosed with PVD were more likely to have had dystocia than cows without PVD (Table 1). Treatment was associated $(P<0.01)$ with prevalence of retained fetal membranes because PVD cows (PBS, LPS150, and LPS300) were more likely to have had retained fetal membranes than cows without PVD (Table 1). The overall incidence of retained fetal membranes was $3 \%$. Similarly, prevalence of metritis was associated $(P$ $<0.01$ ) with treatment because cows with PVD (PBS, LPS150, and LPS300) were more likely to have been diagnosed with metritis than cows without PVD (Table $1)$. The overall incidence of metritis was $6 \%$.

\section{Uterine Health and Resolution of PVD}

The percentages of cows with mild, moderate, and severe PVD diagnosed with $\geq 10 \%$ PMNL in uterine cytology before intrauterine infusion were 37,52 , and $94 \%$, respectively. Treatment was not associated $(P=$ 0.26 ) with the PMNL count in uterine cytology before 
Table 1. Distribution of cows calving twins and male calves and incidence of postpartum health disorders among cows positive for purulent vaginal discharge (PVD) and cows without PVD

\begin{tabular}{|c|c|c|c|c|c|}
\hline \multirow[b]{2}{*}{ Items } & \multicolumn{4}{|c|}{ Treatment $^{1}$} & \multirow[b]{2}{*}{$P$-value } \\
\hline & PBS & LPS150 & LPS300 & No PVD & \\
\hline \multicolumn{6}{|l|}{ Adjusted odds ratio $(95 \% \mathrm{CI})$} \\
\hline Male calf & $0.93(0.60,1.44)$ & $1.36(0.88,2.09)$ & $0.97(0.63,1.50)$ & Referent & 0.55 \\
\hline Twins & $1.91^{\mathrm{ab}}(0.58,6.28)$ & $3.28^{\mathrm{a}}(1.26,8.52)$ & $1.88^{\mathrm{ab}}(0.57,6.20)$ & Referent $^{\mathrm{b}}$ & 0.06 \\
\hline Dystocia & $3.69^{\mathrm{a}}(1.83,7.44)$ & $4.36^{\mathrm{a}}(2.30,8.27)$ & $4.82^{\mathrm{a}}(2.55,9.10)$ & Referent $^{\mathrm{b}}$ & $<0.01$ \\
\hline Retained fetal membranes & $9.76^{\mathrm{a}}(4.45,21.41)$ & $9.49^{\mathrm{a}}(4.40,20.46)$ & $7.07^{\mathrm{a}}(3.03,16.51)$ & Referent $^{\mathrm{b}}$ & $<0.01$ \\
\hline \multicolumn{6}{|l|}{ Incidence, \% (no.) } \\
\hline Male calf & $47.06(85)$ & $56.18(89)$ & $47.73(88)$ & $47.98(2,630)$ & - \\
\hline Twins & $3.53(85)$ & $5.62(89)$ & $3.41(88)$ & $1.86(2,630)$ & - \\
\hline Dystocia & $11.76(85)$ & $14.61(89)$ & $14.77(88)$ & $3.42(2.630)$ & - \\
\hline Retained fetal membranes & $12.64(87)$ & $12.09(91)$ & $8.99(89)$ & $1.69(2,664)$ & - \\
\hline Metritis & $26.44(87)$ & $23.08(91)$ & $19.10(89)$ & $4.02(2,664)$ & - \\
\hline
\end{tabular}

${ }^{\mathrm{a}, \mathrm{b}}$ Within row, values with lowercase letters are different $(P \leq 0.05)$.

${ }^{1}$ Treatments: PBS $=$ cows with PVD treated with $20 \mathrm{~mL}$ of PBS; LPS150 = cows with PVD treated with $150 \mu \mathrm{g}$ of Escherichia coli LPS in 20 $\mathrm{mL}$ of PBS; LPS300 = cows with PVD treated with $300 \mu \mathrm{g}$ of $E$. coli LPS in $20 \mathrm{~mL}$ of PBS; cows without PVD $=$ cows with $<50 \%$ of pus in exudate retrieved from vagina.

intrauterine infusion. The count of PMNL in uterine cytology on $\mathrm{d} 1$ and 2 after intrauterine infusion was not affected $(P=0.13)$ by treatment or by the interaction between treatment and day relative to infusion $(P$ $=0.93$ ). Day relative to intrauterine infusion, however, was associated $(P<0.01)$ with PMNL count in uterine cytology (Figure 1). On d 7 after intrauterine infusion no differences were observed $(P=0.39)$ among treatments regarding PMNL count in uterine cytology (Figure 1). Among PBS cows, a 5\% relative increase occurred in PMNL count in uterine cytology from d 0 to $1(P=0.05)$, but no differences in PMNL count were observed between d 0 and $2(P=0.79)$ and between $\mathrm{d} 0$ and $7(P=0.53)$. Among LPS150 cows, 54 and $31 \%$ increases in PMNL count occurred between d 0 and $1(P$ $<0.01)$ and between d 0 and $2(P<0.01)$, respectively, but no $(P=0.12)$ differences were observed between $\mathrm{d}$ 0 and 7 . Among LPS300 cows, 48 and $30 \%$ increases in PMNL count occurred between d 0 and $1(P<0.01)$ and between d 0 and $2(P<0.01)$, respectively, but no $(P=0.67)$ difference was observed between $\mathrm{d} 0$ and 7 .

Treatment was not associated $(P=0.16)$ with the likelihood of cows with $\geq 10 \%$ PMNL in uterine cytology sample collected immediately before treatment, which was 58\% (Table 2). Fifty-eight percent of cows with PVD had $\geq 10 \%$ PMNL in uterine cytology sample collected immediately before treatment. Treatment did not affect the likelihood of cows with $\geq 10 \%$ PMNL in uterine cytology $1 \mathrm{~d}(P=0.36), 2 \mathrm{~d}(P=0.79)$, and 7 $\mathrm{d}(P=0.12)$ after intrauterine infusion (Table 2$)$. The percentages of cows with $>10 \%$ PMNL in uterine cytology 1,2 , and $7 \mathrm{~d}$ after intrauterine infusion were 88.3 , 84.2 , and $62.6 \%$, respectively. The overall prevalence of PVD 7 and $28 \mathrm{~d}$ after intrauterine infusion was 61 and
$12 \%$, respectively. Treatment did not affect the likelihood of PVD $7 \mathrm{~d}(P=0.47)$ and $28 \mathrm{~d}(P=0.69)$ after intrauterine infusion (Table 2).

\section{Reproductive Performance}

Treatment had no effect on average DIM at first postpartum AI $(P=0.59)$ or the likelihood of cows receiving the first postpartum AI upon detected estrus $(P=0.99 ;$ Table 3$)$. The likelihood of pregnancy at 35 $\pm 6 \mathrm{~d}(P<0.01)$ and $66 \pm 3 \mathrm{~d}(P<0.01)$ after first

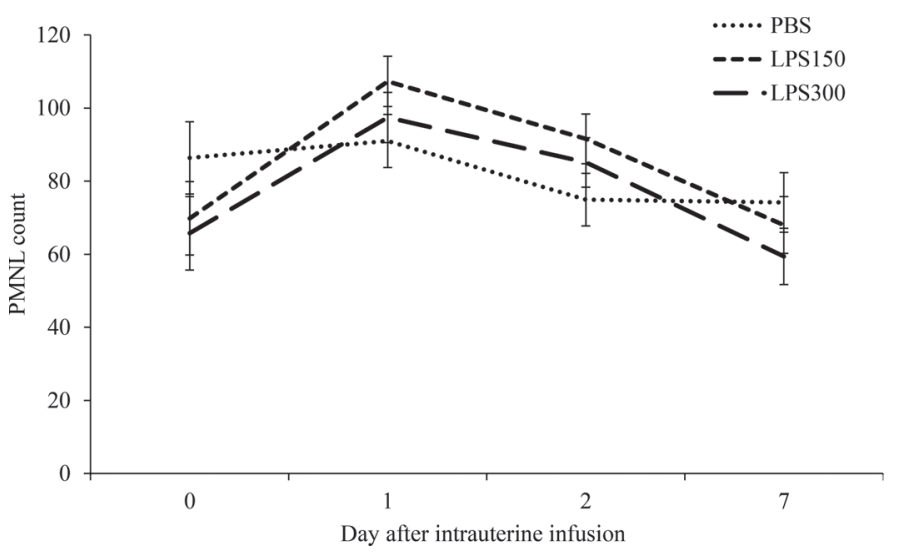

Figure 1. Effect of intrauterine treatment of dairy cows positive for purulent vaginal discharge (PVD) with Escherichia coli LPS on count of PMNL in endometrial cytology. Treatments: PBS = cows with PVD treated with $20 \mathrm{~mL}$ of PBS; LPS150 = cows with PVD treated with $150 \mu \mathrm{g}$ of $E$. coli LPS in $20 \mathrm{~mL}$ of PBS; LPS300 = cows with PVD treated with $300 \mu \mathrm{g}$ of E. coli LPS in $20 \mathrm{~mL}$ of PBS. Day 0 : effect of treatment, $P=0.26$. Days 1 and 2: effect of treatment, $P$ $=0.13$; effect of day, $P<0.01$; effect of the interaction between treatment and day, $P=0.93$. Day 7: effect of treatment, $P=0.39$. Error bars represent SEM. 
postpartum AI were affected by treatment (Table 3 ). At $35 \pm 6 \mathrm{~d}$ after first postpartum AI PBS cows were less likely $(P<0.01)$ to be pregnant than LPS150 cows and cows without PVD, whereas PBS cows tended to be less likely $(P=0.08)$ to be pregnant than LPS300 cows. Cows without PVD were more likely $(P<0.01)$ to be pregnant than LPS300 cows (Table 3). At 66 $\pm 3 \mathrm{~d}$ after first postpartum AI PBS cows were less likely to be pregnant than LPS150 cows $(P=0.01)$ and cows without PVD $(P<0.01)$. Cows without PVD were $(P<0.01)$ more likely to be pregnant $66 \pm 3 \mathrm{~d}$ after first postpartum AI than LPS300 cows (Table 3). Treatment did not affect $(P=0.25)$ the likelihood of pregnancy loss from 35 to $66 \mathrm{~d}$ after first postpartum AI (Table 3). Figure 2 depicts the percentage of cows pregnant and the percentage of cows with pregnancy loss after the first and second postpartum AI.

No differences were observed $(P=0.53)$ among treatments regarding average DIM at second postpartum AI (Table 3). Cows in the PBS, LPS150, and LPS300 treatments were less likely $(P \leq 0.01)$ to receive the second postpartum AI upon detected estrus than cows without PVD, but no differences were observed among cows diagnosed with PVD (Table 3). Cows in the PBS and LPS300 treatments were less likely to be diagnosed pregnant at $35 \pm 6 \mathrm{~d}(P<0.01)$ and $66 \pm 3 \mathrm{~d}(P<$ $0.01)$ after second postpartum AI than cows without PVD (Table 3). Cows in the LPS150 treatment tended to be less likely to be diagnosed pregnant at $35 \pm 6 \mathrm{~d}$ $(P=0.08)$ and $66 \pm 3 \mathrm{~d}(P=0.09)$ after the second postpartum AI than cows without PVD (Table 3). Treatment had no effect $(P=0.90)$ on likelihood of pregnancy loss between 35 and $66 \mathrm{~d}$ after the second postpartum AI (Table 3).

The likelihood of cows being deemed not eligible for AI by 200 DIM was not affected $(P=0.86)$ by treatment (Table 3). Hazard of pregnancy up to 200 d postpartum was reduced for PBS $(P=0.02)$ and LPS300 $(P=0.02)$ cows compared with cows without PVD and tended $(P=0.08)$ to be reduced for LPS150 cows compared with cows without PVD (Table 3 ). The mean $( \pm \mathrm{SEM})$ intervals from calving to establishment of pregnancy were $124.00 \pm 4.78,109.64 \pm 4.48,118.02$ \pm 4.59 , and $99.94 \pm 0.86 \mathrm{~d}$ for PBS, LPS150, LPS300, and cows without PVD, respectively (Figure 3). The median intervals from calving to establishment of pregnancy were 140.5, 107.5, 135.5, and $84 \mathrm{~d}$ for PBS, LPS150, LPS300, and cows without PVD, respectively (Figure 3).

\section{DISCUSSION}

The hypotheses of the current experiment were that treatment of cows with PVD with E. coli LPS would elicit a transient inflammation with rapid influx of PMNL to the uterus, which would result in improvements in uterine health and consequently improve reproductive performance. Although the overall effect of treatment on PMNL count in uterine cytology was not statistically significant, the intrauterine infusion with $E$. coli LPS may have produced an acute and prolonged rise in PMNL count in the uterus. In fact, PBS treatment only produced a $5 \%$ increase in PMNL count within $24 \mathrm{~h}$ after intrauterine infusion, whereas intrauterine infusion with LPS produced a 50\% increase in PMNL count within $24 \mathrm{~h}$ that was still present at $48 \mathrm{~h}$ after treatment. The PMNL count in the uterine cytology of LPS150 and LPS300 cows only returned to pretreatment levels at $7 \mathrm{~d}$ after intrauterine infusion. Hussain and Daniel (1992) demonstrated that intrauterine infusion of $100 \mu \mathrm{g}$ of E. coli LPS in cows with Streptococcus agalactiae experimentally induced endometritis resulted in increased intrauterine leukocyte count and $N$-acetyl- $\beta$-D-glucosaminidase activity. In fact, cows

Table 2. Effect of intrauterine treatment of dairy cows with Escherichia coli LPS on uterine cytology and risk of purulent vaginal discharge (PVD) following treatment

\begin{tabular}{|c|c|c|c|c|}
\hline Item & \multicolumn{3}{|c|}{ Treatment $^{1}$} & $P$-value \\
\hline \multicolumn{5}{|c|}{$\begin{array}{l}\text { Likelihood of cows having } \geq 10 \% \text { PMNL in uterine cytology, } \\
\text { AOR }(95 \% \mathrm{CI})^{2}\end{array}$} \\
\hline d 0 (before treatment) & Referent & $0.85(0.28,2.53)$ & $0.33(0.10,1.09)$ & 0.16 \\
\hline $1 \mathrm{~d}$ after treatment & Referent & $3.43(0.62,18.97)$ & $1.76(0.38,8.14)$ & 0.36 \\
\hline $2 \mathrm{~d}$ after treatment & Referent & $0.97(0.28,3.28)$ & $1.47(0.40,5.44)$ & 0.79 \\
\hline $7 \mathrm{~d}$ after treatment & Referent & $1.05(0.40,2.73)$ & $1.77(0.65,4.86)$ & 0.47 \\
\hline $28 \mathrm{~d}$ after treatment & Referent & $1.45(0.29,7.28)$ & $0.70(0.12,4.01)$ & 0.69 \\
\hline
\end{tabular}

${ }^{1}$ Treatments: PBS $=$ cows with PVD treated with $20 \mathrm{~mL}$ of PBS; LPS150 = cows with PVD treated with $150 \mu \mathrm{g}$ of E. coli LPS in $20 \mathrm{~mL}$ of PBS; LPS300 = cows with PVD treated with $300 \mu \mathrm{g}$ of E. coli LPS in $20 \mathrm{~mL}$ of PBS.

${ }^{2} \mathrm{AOR}(95 \% \mathrm{CI})=$ adjusted odds ratio $(95 \% \mathrm{CI})$. 
INTRAUTERINE LIPOPOLYSACCHARIDE AND REPRODUCTION

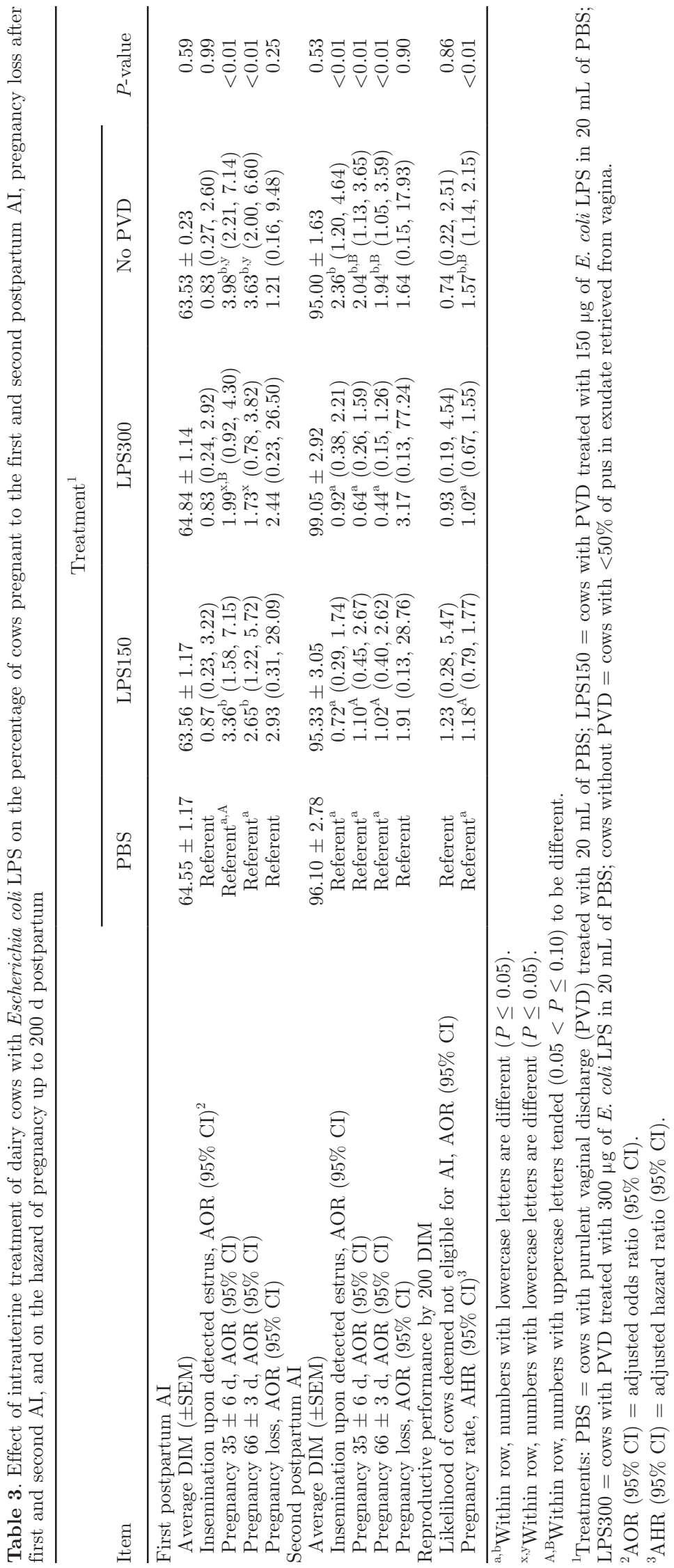


receiving intrauterine LPS had a greater number of PMNL in the uterus up to approximately $5 \mathrm{~d}$ after infusion (Hussain and Daniel, 1992), which is similar to what was demonstrated in the current experiment. In another experiment with crossbred cows, Singh et al. (2000) demonstrated that intrauterine infusion of 100 $\mu \mathrm{g}$ of E. coli LPS in cows with endometritis resulted in elimination of uterine bacterial infection in $75 \%$ of the cows and increased intrauterine total leukocyte count, percentage of PMNL in uterine cytology, and percentage of live PMNL in the uterus (Singh et al., 2000). In a companion study, we described that intrauterine infusion with LPS resulted in up-regulation of expression of MAC-1 in peripheral PMNL and increased percentage of peripheral PMNL positive for phagocytosis and oxi-
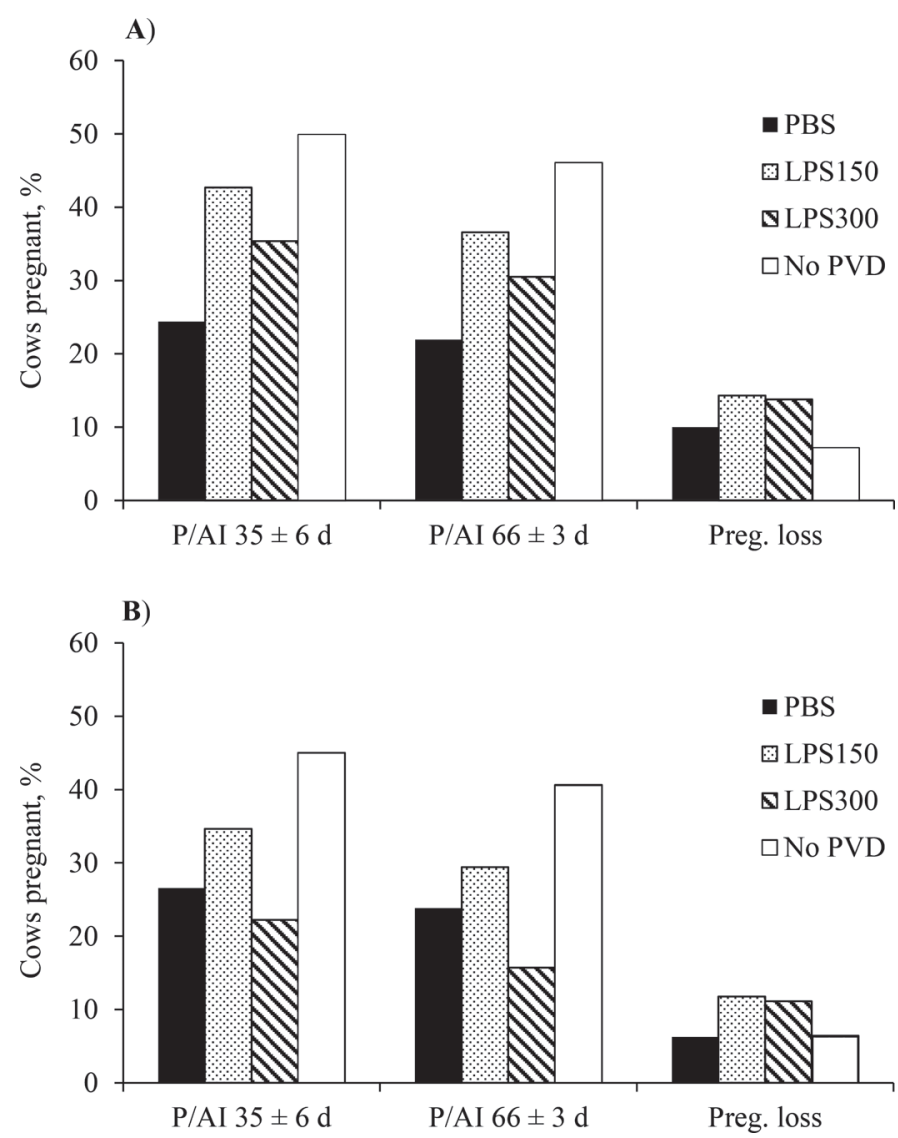

Figure 2. (A) Percentage of cows pregnant (P/AI) at $35 \pm 6$ and $66 \pm 3 \mathrm{~d}$ after the first postpartum AI and percentage of cows with pregnancy loss from $35 \pm 6$ and $66 \pm 3 \mathrm{~d}$ after the first postpartum AI according to treatment. (B) Percentage of cows pregnant at $(\mathrm{P} / \mathrm{AI})$ $35 \pm 6$ and $66 \pm 3 \mathrm{~d}$ after the second postpartum AI and percentage of cows with pregnancy (Preg.) loss from $35 \pm 6$ and $66 \pm 3 \mathrm{~d}$ after the second postpartum AI according to treatment. Treatments: PBS = cows with purulent vaginal discharge (PVD) treated with $20 \mathrm{~mL}$ of PBS; LPS150 = cows with PVD treated with $150 \mu \mathrm{g}$ of Escherichia coli LPS in $20 \mathrm{~mL}$ of PBS; LPS300 = cows with PVD treated with 300 $\mu \mathrm{g}$ of $E$. coli LPS in $20 \mathrm{~mL}$ of PBS; No PVD = cows with $<50 \%$ of pus in exudate retrieved from vagina. dative burst (Moraes et al., 2017). MAC-1 is a member of the $\beta 2$-integrins subfamily and plays an important role in the firm adhesion and diapedesis of PMNL through endothelium during inflammation (Carlos and Harlan, 1994), which may explain the greater and more sustained influx of PMNL in the uterus of LPS150 and LPS300 cows.

Despite the greater influx of PMNL in the uterus of cows receiving intrauterine E. coli LPS, the likelihood of cows being diagnosed with PVD 7 and $28 \mathrm{~d}$ after intrauterine infusion was not affected by treatment. The sources of pus detected in the cranial vagina by the Metricheck device are the vagina, cervix, or uterus. Considering that the treatment was applied intra-uterus in the present experiment, it is possible that the Metricheck exam was not sensitive enough to detect any improvements in uterine health. The rationale for changing the nomenclature for describing cows with pus accumulation in the cranial vagina from endometritis to PVD is based on uterine inflammation not always being present in cows with PVD (Sheldon et al., 2006; Dubuc et al., 2010). In the current experiment, however, PVD was highly associated with uterine diseases that are known to compromise reproductive performance (LeBlanc et al., 2002b; Goshen and Shpigel, 2006; Denis-Robichaud and Dubuc, 2015a; Dubuc et al., 2010). Sixty-nine percent of cows diagnosed with PVD had $\geq 6 \%$ PMNL in the uterine cytology sample collected immediately before treatment, a condition

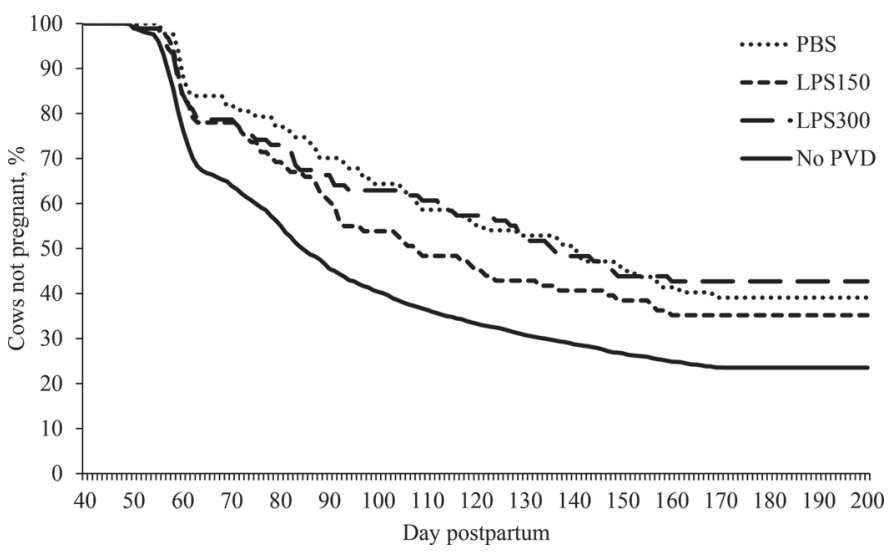

Figure 3. Effect of intrauterine treatment of dairy cows with Escherichia coli LPS on survival distribution of time to pregnancy up to $200 \mathrm{~d}$ postpartum. Treatments: PBS = cows with purulent vaginal discharge (PVD) treated with $20 \mathrm{~mL}$ of PBS; LPS150 = cows with PVD treated with $150 \mu \mathrm{g}$ of $E$. coli LPS in $20 \mathrm{~mL}$ of PBS; LPS300 = cows with PVD treated with $300 \mu \mathrm{g}$ of $E$. coli LPS in $20 \mathrm{~mL}$ of PBS; No PVD $=$ cows with $<50 \%$ of pus in exudate retrieved from vagina. Wilcoxon test of equality: $P<0.01$. Mean $( \pm$ SEM $)$ and median, respectively, intervals from calving to establishment of pregnancy: PBS $=124.00 \pm 4.78$ and $140.5 \mathrm{~d}$; LPS150 $=109.64 \pm 4.48$ and $107.5 \mathrm{~d}$; LPS300 $=118.02 \pm 4.59$ and $135.5 \mathrm{~d} ;$ No PVD $=99.94 \pm 0.86$ and $84 \mathrm{~d}$. 
associated with reduced reproductive performance (Denis-Robichaud and Dubuc, 2015a). Additionally, the prevalence of dystocia, retained fetal membranes, and metritis were significantly greater for cows diagnosed with PVD compared with cows without PVD, which corroborates the findings of other research groups that demonstrated similar associations among postpartum uterine disorders and increased risk for PVD (Galvão, 2012).

Cows that received $150 \mu \mathrm{g}$ of $E$. coli LPS were more likely to be pregnant after the first postpartum AI than PBS cows. Similar improvements in reproductive performance of cows with endometritis following LPS intrauterine infusion have been demonstrated (Singh et al., 2000). Furthermore, PBS cows were less likely to be pregnant after the first postpartum AI compared with cows without PVD. The likelihood of pregnancy after the first postpartum AI did not differ between LPS150 cows and cows without PVD, but the power of this statistical test was insufficient $(1-\beta=0.22)$ to determine that no differences between LPS150 cows and cows without PVD exist. Treatment of cows with PVD with $300 \mu \mathrm{g}$ of $E$. coli LPS did not improve the likelihood of pregnancy after first postpartum AI. We expected that the intrauterine treatment of cows with PVD with LPS would result in greater and more sustained influx of PMNL into the uterus and that, despite an initial increase of pus in the vagina, resolution of PVD would then improve reproductive performance. Cows receiving the LPS150 and LPS300 treatments had similar responses regarding PMNL count in the uterine cytology from 1 to $7 \mathrm{~d}$ after treatment and prevalence of PVD at 7 and $28 \mathrm{~d}$ after treatment. The intrauterine infusion with LPS possibly improved the likelihood of pregnancy after the first AI by eliminating bacterial contamination or altering the uterine microbiome, neither of which was evaluated in the current experiment. Singh et al. (2000) demonstrated intrauterine infusion with $100 \mu \mathrm{g}$ of $E$. coli LPS reduced the percentage of cows with bacteria isolated from the uterus. Additionally, Santos and Bicalho (2012) reported that the bacterial core community in the uterus of healthy cows and cows with uterine infections (metritis and endometritis) are different. The intrauterine infusion with $300 \mu \mathrm{g}$ of $E$. coli LPS may have produced an excessive intrauterine inflammatory response that caused an excessive sloughing of the endometrium, but the data presented herein and the lack of histology data prevent us from confirming this possibility. One may also speculate that intrauterine infusion with $300 \mu \mathrm{g}$ of $E$. coli LPS may have affected ovarian function because postpartum uterine infection negatively affects ovarian function (Sheldon et al., 2002, 2009; Williams et al., 2007). Although Williams et al. (2008) demonstrated that heifers that received $3 \mu \mathrm{g} / \mathrm{kg}$ of LPS intra-uterus were less likely to ovulate and those that ovulated had reduced progesterone concentrations than heifers treated with PBS, we demonstrated in a companion study that the concentrations of progesterone 1,2 , and $7 \mathrm{~d}$ after intrauterine infusion with LPS $(150 \mu \mathrm{g}$ and $300 \mu \mathrm{g}$ ) and PBS were not different (Moraes et al., 2017). Additional experiments are necessary to better understand the mechanisms through which different doses of LPS affect P/AI of cows with PVD.

Despite improvements in the likelihood of pregnancy after the first postpartum AI among LPS150 cows, they tended to have reduced likelihood of pregnancy after the second postpartum AI and tended to have reduced hazard ratio for pregnancy by 200 DIM compared with cows without PVD. It is not clear why treatment with $150 \mu \mathrm{g}$ of LPS did not have a long-term effect on the fertility of cows diagnosed with PVD. We speculate that such treatment restored fertility of cows that had milder uterine disorders, but it was unable to improve fertility of cows with more severe uterine pathologies. Singh et al. (2000) demonstrated significant improvements in the likelihood of pregnancy of cows with PVD treated with intrauterine infusion with LPS on the day of AI upon detected estrus. Although treating endometritic cows on the day of estrus could potentiate LPS immunomodulatory action because of inherently reduced progesterone concentrations (Siiteri et al., 1977; Hansen, 2013), in the current experiment cows were treated at approximately 31 DIM, almost 30 $\mathrm{d}$ before first postpartum AI. Therefore, it is possible that the mechanisms associated with improved fertility in the current experiment and Singh et al. (2000) are different. Treatment of cows diagnosed with PVD and endometritis at $35 \pm 7$ DIM with cephapirin benzathine improved the likelihood of pregnancy following the first postpartum AI compared with untreated cows (Denis-Robichaud and Dubuc, 2015b). Actually, similar to the current experiment, the likelihood of pregnancy after the first postpartum AI of cows with PVD treated with cephapirin benzathine was restored to the level of cows without PVD (Denis-Robichaud and Dubuc, 2015b). Treatment of cows with PVD with cephapirin benzathine has produced consistent improvements in likelihood of pregnancy after the first postpartum AI compared with untreated cows (LeBlanc et al., 2002a; Runciman et al., 2008).

In the current experiment all cows were treated with $\mathrm{PGF}_{2 \alpha}$ approximately 10 and $24 \mathrm{~d}$ after the intrauterine infusions with LPS and PBS. The effects of treating cows with endometritis and PVD with sequential injections of $\mathrm{PGF}_{2 \alpha}$ on fertility are controversial, with some authors reporting improvement in fertility (Kasimanickam et al., 2005; McDougall et al., 2013) but others 
reporting no improvement in fertility (Hendricks et al., 2006; Dubuc et al., 2011). In a recent meta-analysis, data from 6 experiments were used to evaluate the interval from calving to first postpartum AI and from calving to conception of cows with endometritis treated with $\mathrm{PGF}_{2 \alpha}$ (21-50 DIM) or left untreated (Haimerl et al., 2013). Surprisingly, in this meta-analysis, treatment with $\mathrm{PGF}_{2 \alpha}$ resulted in longer interval from calving to conception (Haimerl et al., 2013). Therefore, we speculate that the improvements in likelihood of pregnancy to the first postpartum AI observed among cows with PVD treated with $150 \mu \mathrm{g}$ of LPS would be observed if the cows had not received sequential injections of $\mathrm{PGF}_{2 \alpha}$.

\section{CONCLUSIONS}

Alternative therapies to antimicrobial treatment of lactating dairy cows positive for PVD are necessary in the United States because of the lack of an approved antimicrobial with proven efficacy. Considering the importance of PVD for reproductive performance and the close relationship between reproductive efficiency and profitability of dairy herds, efficacious treatments for PVD must result in cure of the condition and restoration of reproductive efficiency to the level of unaffected cows. The incidence of postpartum uterine disorders was higher among cows diagnosed with PVD and, as expected, cows with PVD treated with PBS had reduced reproductive performance compared with cows without PVD. Treatment of cows with PVD with 150 $\mu \mathrm{g}$ of LPS improved the likelihood of pregnancy after the first postpartum AI, but treatment of cows with PVD with $300 \mu \mathrm{g}$ of LPS did not improve fertility. Further experiments are necessary to determine the exact mechanism through which LPS restores fertility in cows with PVD.

\section{ACKNOWLEDGMENTS}

The authors thank the owner and staff of the collaborating dairy (Nicollet, MN) for the use of their cows and facilities and the Grant-in-Aid Program of the Office of the Vice President for Research of the University of Minnesota for funding this experiment.

\section{REFERENCES}

Carlos, T. M., and J. M. Harlan. 1994. Leukocyte-endothelial adhesion molecules. Blood 84:2068-2101.

Denis-Robichaud, J., and J. Dubuc. 2015a. Determination of optimal diagnostic criteria for purulent vaginal discharge and cytological endometritis in dairy cows. J. Dairy Sci. 98:6848-6855.

Denis-Robichaud, J., and J. Dubuc. 2015b. Randomized clinical trial of intrauterine cephapirin infusion in dairy cows for the treat- ment of purulent vaginal discharge and cytological endometritis. J. Dairy Sci. 98:6856-6864.

Dubuc, J., T. F. Duffield, K. E. Leslie, J. S. Walton, and S. J. LeBlanc. 2010. Definitions and diagnosis of postpartum endometritis in dairy cows. J. Dairy Sci. 93:5225-5233.

Dubuc, J., T. F. Duffield, K. E. Leslie, J. S. Walton, and S. J. LeBlanc. 2011. Randomized clinical trial of antibiotic and prostaglandin treatments for uterine health and reproductive performance in dairy cows. J. Dairy Sci. 94:1325-1338.

Ferguson, J. D., D. T. Galligan, and N. Thomsen. 1994. Principal descriptors of body condition score in Holstein cows. J. Dairy Sci. 77:2695-2703

Galvão, K. 2012. Postpartum uterine diseases in dairy cows. Anim. Reprod. 9:290-296.

Goshen, T., and N. Y. Shpigel. 2006. Evaluation of intra-uterine antibiotic treatment of clinical metritis and retained fetal membranes in dairy cows. Theriogenology 66:2210-2218.

Haimerl, P., W. Heuwieser, and S. Arlt. 2013. Therapy of bovine endometritis with prostaglandin F2 $\alpha$ : A meta-analysis. J. Dairy Sci 96:2973-2987.

Hansen, P. J. 2013. Maternal immunological adjustments to pregnancy and parturition in ruminants and possible implications for postpartum uterine health: Is there a prepartum-postpartum nexus? J. Anim. Sci. 91:1639-1649.

Hendricks, K. E., J. A. Bartolome, P. Melendez, C. Risco, and L. F. Archbald. 2006. Effect of repeated administration of PGF2alpha in the early post partum period on the prevalence of clinical endometritis and probability of pregnancy at first insemination in lactating dairy cows. Theriogenology 65:1454-1464.

Huang, J., V. Canadien, G. Y. Lam, B. E. Steinberg, M. C. Dinauer, M. A. Magalhães, M. Glogauer, S. Grinstein, and J. H. Brumell. 2009. Activation of antibacterial autophagy by NADPH oxidases. Proc. Natl. Acad. Sci. USA 106:6226-6231.

Hussain, A. M., and R. C. W. Daniel. 1992. Effects of intrauterine infusion of Escherichia coli endotoxin in normal cows and in cows with endometritis induced by experimental infection with Streptococcus agalactiae. Theriogenology 37:791-810.

Kasimanickam, R., T. F. Duffield, R. A. Foster, C. J. Gartley, K. E. Leslie, J. S. Walton, and W. H. Johnson. 2005. The effect of a single administration of cephapirin or cloprostenol on the reproductive performance of dairy cows with subclinical endometritis. Theriogenology 63:818-830.

LeBlanc. S. J., T. F. Duffield, K. E. Leslie, K. G. Bateman, G. P. Keefe, J. S. Walton, and W. H. Johnson. 2002a. The effect of treatment of clinical endometritis on reproductive performance in dairy cows. J. Dairy Sci. 85:2237-2249.

LeBlanc, S. J., T. F. Duffield, K. E. Leslie, K. G. Bateman, G. P. Keefe, J. S. Walton, and W. H. Johnson. 2002b. Defining and diagnosing postpartum clinical endometritis and its impact on reproductive performance in dairy cows. J. Dairy Sci. 85:2223-2236.

Li, Q., and I. M. Verma. 2002. NF-kappaB regulation in the immune system. Nat. Rev. Immunol. 2:725-734.

Lu, Y. C., W. C. Yeh, and P. S. Ohashi. 2008. LPS/TLR4 signal transduction pathway. Cytokine 42:145-151.

Masera, J., B. K. Gustafsson, M. M. Afiefy, C. M. Stowe, and G. P. Bergt. 1980. Disposition of oxytetracycline in the bovine genital tract: Systemic vs intra-uterine administration. J. Am. Vet. Med. Assoc. 176:1099-1102.

McDougall, S., M. de Boer, C. Compton, and S. J. Leblanc. 2013. Clinical trial of treatment programs for purulent vaginal discharge in lactating dairy cattle in New Zealand. Theriogenology 79:11391145 .

McDougall, S., R. Macaulay, and C. Compton. 2007. Association between endometritis diagnosis using a novel intravaginal device and reproductive performance in dairy cattle. Anim. Reprod. Sci. 99:9-23.

McLaughlin, C. L., E. P. Stanisiewski, C. A. Risco, J. E. P. Santos, G E. Dahl, R. C. Chebel, C. LaGrowa, C. Daughertya, L. Brysona, D. Weigela, J. Hallberga, and M. J. Lucas. 2013. Evaluation of ceftiofur crystalline free acid sterile suspension for control of metritis in high-risk lactating dairy cows. Theriogenology 79:725-734. 
Mogensen, T. H. 2009. Pathogen recognition and inflammatory signaling in innate immune defenses. Clin. Microbiol. Rev. 22:240-273.

Moraes, J. G. N., P. R. B. Silva, L. G. D. Mendonça, A. A. Scanavez, J. C. C. Silva, K. N. Galvão, M. A. Ballou, M. Worku, and R. C. Chebel. 2017. Effects of intra-uterine infusion with Escherichia coli lipopolysaccharide on endometrial mRNA gene expression and innate immune and inflammatory responses of Jersey cows diagnosed with purulent vaginal discharge. J. Dairy Sci. 100:47844796. https://doi.org/10.3168/jds.2016-11643.

O'Neill, L. A., and A. G. Bowie. 2007. The family of five: TIR-domaincontaining adaptors in toll-like receptor signalling. Nat. Rev. Immunol. 7:353-364.

Park, B. S., D. H. Song, H. M. Kim, B. S. Choi, H. Lee, and J. O. Lee. 2009. The structural basis of lipopolysaccharide recognition by the TLR4-MD-2 complex. Nature 458:1191-1195.

Runciman, D. J., G. A. Anderson, J. Malmo, and G. M. Davis. 2008. Effect of intrauterine treatment with cephapirin on the reproductive performance of seasonally calving dairy cows at risk of endometritis following periparturient disease. Aust. Vet. J. 86:250-258.

Santos, T. M., and R. C. Bicalho. 2012. Diversity and succession of bacterial communities in the uterine fluid of postpartum metritic, endometritic and healthy dairy cows. PLoS One 7:e53048.

Schroder, K., P. J. Hertzog, T. Ravasi, and D. A. Hume. 2004. Interferon-gamma: An overview of signals, mechanisms and functions. J. Leukoc. Biol. 75:163-189.

Sheldon, I. M., J. Cronin, L. Goetze, G. Donofrio, and H. J. Schuberth. 2009. Defining postpartum uterine disease and the mechanisms of infection and immunity in the female reproductive tract in cattle. Biol. Reprod. 81:1025-1032.

Sheldon, I. M., G. S. Lewis, S. LeBlanc, and R. O. Gilbert. 2006. Defining postpartum uterine disease in cattle. Theriogenology 65:1516-1530.

Sheldon, I. M., D. E. Noakes, A. N. Rycroft, D. U. Pfeiffer, and H. Dobson. 2002. Influence of uterine bacterial contamination after parturition on ovarian dominant follicle selection and follicle growth and function in cattle. Reproduction 123:837-845.

Siiteri, P. K., F. Febres, L. E. Clemens, R. J. Chang, B. Gondos, and D. Stites. 1977. Progesterone and maintenance of pregnancy: Is progesterone nature's immunosuppressant? Ann. N. Y. Acad. Sci. 286:384-397.

Singh, J., S. S. Sidhu, G. S. Dhaliwal, G. R. Pangaonkar, A. S. Nanda, and A. S. Grewal. 2000. Effectiveness of lipopolysaccharide as an intra-uterine immunomodulator in curing bacterial endometritis in repeat breeding cross-bred cows. Anim. Reprod. Sci. 59:159-166.

Williams, E. J., D. P. Fischer, D. E. Noakes, G. C. England, A. Rycroft, H. Dobson, and I. M. Sheldon. 2007. The relationship between uterine pathogen growth density and ovarian function in the postpartum dairy cow. Theriogenology 68:549-559.

Williams, E. J., K. Sibley, A. N. Miller, E. A. Lane, J. Fishwick, D. M. Nash, S. Herath, G. C. England, H. Dobson, and I. M. Sheldon. 2008. The effect of Escherichia coli lipopolysaccharide and tumour necrosis factor alpha on ovarian function. Am. J. Reprod. Immunol. 60:462-473. 